\title{
Maths Arcade at Sheffield Hallam University: Developments made in a new space
}

Claire Cornock, Department of Engineering and Mathematics, Sheffield Hallam University, Sheffield, UK. Email: c.cornock@shu.ac.uk

\begin{abstract}
The Maths Arcade at Sheffield Hallam University has been developed since it was established in 2012. The move to a new space has led to an increase in its popularity and inter-year interactions. It has added to the extensive number of factors that help ease the transition into university. In particular, it now features in the induction week programme and plays a part in our peer assisted learning scheme. In addition to the weekly sessions enjoyed by the students, the Maths Arcade has also been used at a number of events such as the final year de-stress day, and by the Women in Engineering and Mathematics Society. The Maths Arcade has also hosted another Rubik's cube championship.
\end{abstract}

Keywords: Games, recreational mathematics, mathematics community, transition, student support

\section{Background}

The original Maths Arcade was created at the University of Greenwich to stretch stronger students, support the weaker ones and encourage interaction between both staff and students (Bradshaw, 2011). Their objectives included "providing a weekly drop-in session where students could play various strategy board games and puzzles designed to hone and develop strategic thinking, alongside providing a safe place for them to obtain help on tutorial work".

Since then, the Maths Arcade has been rolled out to a number of universities including Manchester, Salford, Leicester, Bath, Nottingham, Keele and Sheffield Hallam (Bradshaw and Rowlett, 2012). After an initial trial (Cornock and Baxter, 2012), the Maths Arcade at Sheffield Hallam University is now run as a weekly session with the focus being on adding to the development of a maths community and giving the students a break from their studies. The sessions take place during term time and the students are welcome to come and play the strategy games or just call in for a cup of tea or coffee. The games vary in their duration and difficulty. Games such as Quarto are very quick to pick up and play, but then the students can develop appropriate strategies which may involve engineering "a situation where your opponent is only left with pieces that give you a win" (Bradshaw, 2011). Some games tend to last a lot longer, such as Ingenious which involves "placing tiles on a board with a clever scoring system" (Bradshaw, 2011). Students are free to choose which games they play from the collection of over twenty games. They can join the Maths Arcade at any point during its weekly slot as the atmosphere is very relaxed and informal, either to join in or watch some of the games. Some students arrive in groups, but those who arrive on their own either join the other students or challenge the staff present.

Despite being set up with first year students in mind, the Maths Arcade is enjoyed by students in all the year groups. Evaluation took place at the end of 2014-15 through a questionnaire sent to all students asking for open responses; a total of thirteen students responded. The majority of the responses from the students have been used from this questionnaire; repeated comments and irrelevant ones have been excluded. Results from another survey on the department's new 
learning space have also been used; nine members of staff and twenty five students made comments on the benefits of the new space. The Maths Arcade wasn't asked about specifically in this questionnaire, but relevant comments have been used. In addition to this, results from a survey about a final year de-stress day have been used as the Maths Arcade was part of this; four students provided comments. Unless otherwise stated, all comments are from the end of year questionnaire on the Maths Arcade.

When the students were asked what they like about the Maths Arcade, the responses included the following comments:

"I like to be able to have a bit of chill out time with my friends playing some games! I enjoyed doing it with Claire as well because she was enthusiastic about it." (First year student)

"Nice break from normal Uni work with friends that gets you thinking in new ways due to the numerous types of games." (Second year student)

"The company and the coffee." (Second year student)

"The way it's helped me make friends." (Second year student)

"Relaxing atmosphere, coffee and interesting games." (Second year student)

"It allows you to get to know the other students who you might not usually talk to and also to get to know some lecturers better." (Placement year student)

"It forced me to step back from work and have a break from work. It enabled me to meet new people and socialise with my peers." (Final year student)

"The chance to mix with other people who may not be in my seminars/lectures." (Final year student)

"Fun, enjoyable, takes your mind off revision." (Final year student)

"I really enjoyed that it took my mind off assignments and revision." (Final year student)

"Yes, it's a very good idea to relieve stress for an hour or two half way through the week!" (Final year student)

\section{New location}

During the first few years, the Maths Arcade was based in a classroom with a timetabled weekly slot. This limited the number of students that attended, even with the added incentive of caffeine and snacks. However, it was still enjoyed by a number of students. Students were asked whether they attended the Maths Arcade when it was in its old environment, how they found it if they went and why they didn't attend if they didn't go. Responses included the following remarks:

"I went every week. It was nice to spend time with other students at uni not doing work. It kept me thinking before my afternoon lecture." (Second year student)

"I did, and it was lovely, it made me make many friends in different years." (Second year student)

"I did not attend. Main reason was due to its location." (Second year student) 
"Maths Arcade was a welcome break from work and conveniently right next to my next tutorial." (Final year student)

"I attended when it was in harmer - I found it was a great break between my lecture and seminar." (Final year student)

“Attended but didn't find it as enjoyable as in the open space in Norfolk." (Final year student)

"I really enjoyed going in first year. It was a nice break from everything else." (Final year student)

In January 2015, the maths subject group moved to a new space. The working area was designed from scratch to encourage interaction between staff and students. Large open plan working areas were created around staff offices that contain lots of space for group work. When the group moved to the new space, it was obvious that the Maths Arcade would move to this area as well. When asked in the separate survey about the new space in general, students mentioned that some of the benefits of the space are that it "creates more of a mathematical community", that its "spacious design has led to a great social atmosphere" and that it brings a "sense of "home". Staff comments have included that it "gives everybody a nice feeling of community and partnership", that it creates a "good atmosphere amongst all maths students of different years", that staff "can easily say a quick hello to students as [they] walk through", and that it's a better space to hold events. When the students were asked in the Maths Arcade questionnaire whether they had attended it in the new space and how they found it, the following comments were received:

"Yes. I loved it in Norfolk I got to speak to people from other years and play games with them. My friends also attended so I got to spend time with them as well!" (First year student)

"It is a really calm atmosphere and you get to talk to students and lecturers. The perfect time for a coffee too!" (Second year student)

"I did, same again, a nice friendly atmosphere." (Second year student)

"Yes and I thoroughly enjoyed it. Perfect location in the middle of the day and really relaxing. The coffee addition was really welcome." (Second year student)

"Very easy to find." (Final year student)

"I found the atmosphere was better in Norfolk but the cakes got eaten too fast!" (Final year student)

"Feels much more sociable in Norfolk." (Final year student)

Since the move to the new space, the popularity of the Maths Arcade has increased. It has also been observed that a number of students and staff now call in just to say hello. When students were asked why they attend the Maths Arcade when they didn't before, the response has always been about the new space making it more appealing. When asked what is better or worse about the Maths Arcade being in the new space, the responses included the following comments:

"It's bigger and it seems more comfortable." (First year student)

"More people see it and come as easier to find as in the maths space. If a game overruns the time, can finish it without losing the room." (Second year student)

“Nicer atmosphere." (Second year student) 
"More people will join." (Second year student)

"The new space enables students and lecturers to easily discuss topics over a game. It is also a perfect location as most lectures/tutorials are close by." (Final year student)

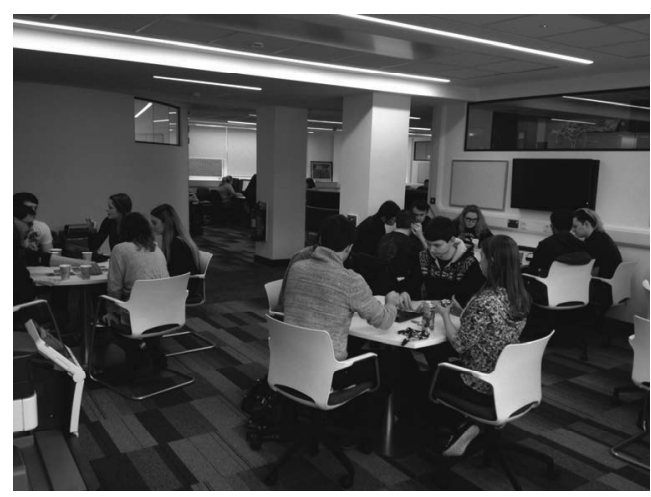

Figure 1. The Maths Arcade in the new space

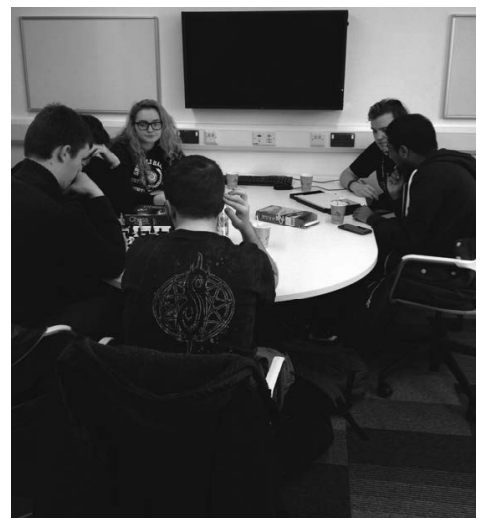

Figure 2. The Maths Arcade in the new space

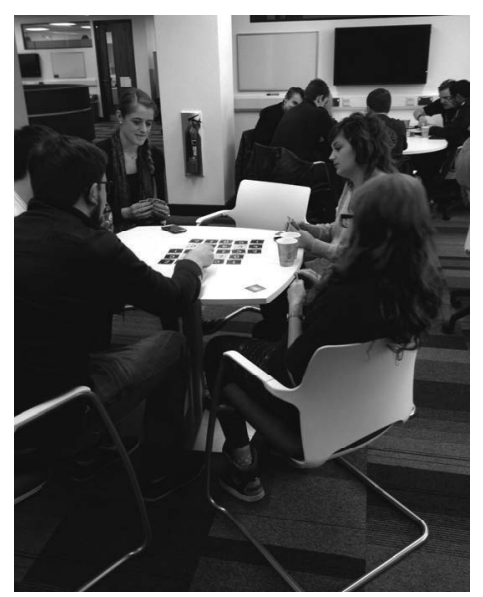

Figure 3. The Maths Arcade in the new space 


\section{Events and uses of the Maths Arcade}

As well as the weekly Maths Arcade sessions, there have been a number of other occasions that the games have made appearances.

\subsection{Induction week and peer assisted learning}

At Sheffield Hallam University, there is a large amount of attention focussed towards easing the transition into university. In addition to the Maths Arcade, other factors that help the maths subject group towards this goal include the use of year tutors for support, an open door policy, an extensive induction week programme, various events held throughout the year and the use of a peer assisted learning (PAL) scheme. The PAL scheme has been running for a number of years (Waldock, 2010) and has recently been thoroughly reviewed and developed. Part of this development has been within the training of the PAL leaders and introduction of the first year students to the scheme.

A number of the factors mentioned above have been combined together. The Maths Arcade now features in the induction week programme. At this session, the students sit with their PAL groups and meet their final year PAL leader. The Arcade is a great ice breaker for the students to get to know each other and their assigned final year leader in a relaxed and informal setting. There were a few comments from students who didn't enjoy the experience during induction week as the Maths Arcade isn't appealing to everyone. The positive responses from the students when they were asked whether they enjoyed the Maths Arcade in induction week included the following:

"Yes because I got to talk to people I hadn't previously and also got to bond with my PAL group." (First year student)

"It was laid back environment and didn't feel awkward." (First year student)

"Yes. Great way to introduce yourself to your classmates. This year's $2^{\text {nd }}$ years went to the 1 st years induction session so I got to meet some of them too." (Second year student)

"Yes, because it allowed me to get know my fellow students a little better." (Placement year student)

"Yes, it was a good ice breaker." (Final year student)

\subsection{Women in Engineering and Mathematics social event}

The games from the Maths Arcade were borrowed by a couple of the students to be used at a social event run by the Women in Engineering and Mathematics Society. They ran games as well as activities and the organisers reported back that the games "were good for people to socialise over, especially when some of the people hadn't been to one of the meetings before". The engineering students who hadn't played many logic games before particularly found them interesting. 


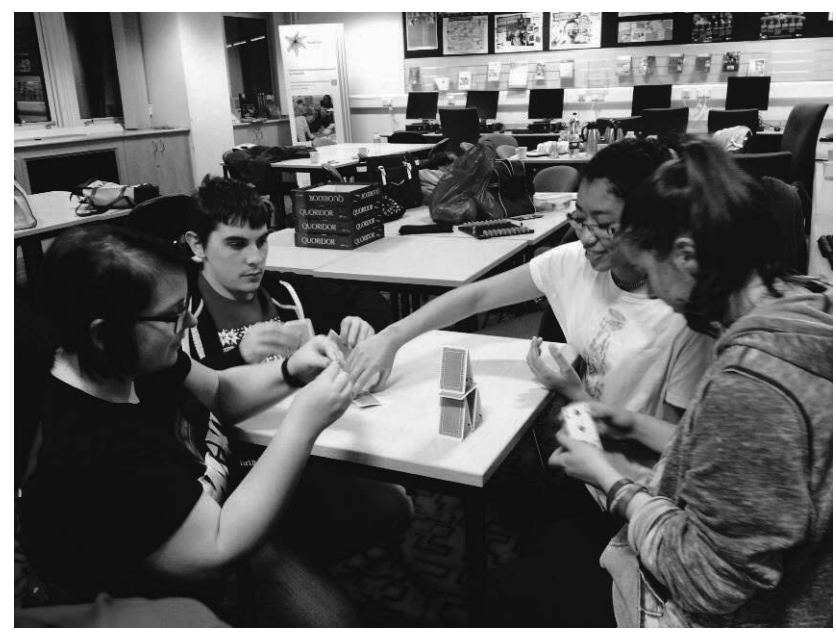

Figure 4. The Women in Engineering and Maths social event

\subsection{Final year de-stress day}

A de-stress day was organised for the final year students in March 2015 when the students were under the most amount of pressure from coursework deadlines, "exactly when it was needed most" as mentioned by a student in response to the de-stress day questionnaire. The focus of the event was on the students' well-being and was attended by most of the final year students at some point throughout the day. Activities and resources included Indian head massages, Lego, bubble wrap, stress balls, knitting, Wii sports, tea and coffee. The Maths Arcade was available throughout the duration of the day and was enjoyed by the students. It has been noted by a member of staff in the survey on the new space that the "Maths Arcade and de-stress day have both taken off because of [the new space]." The students who filled in the questionnaire on the de-stress day found it "fun and relaxing", thought it "was a really nice idea", found it "very enjoyable" and described it as "a nice break". Out of the four students that completed the surveyed, two of them said that they had enjoyed the Maths Arcade at the event.

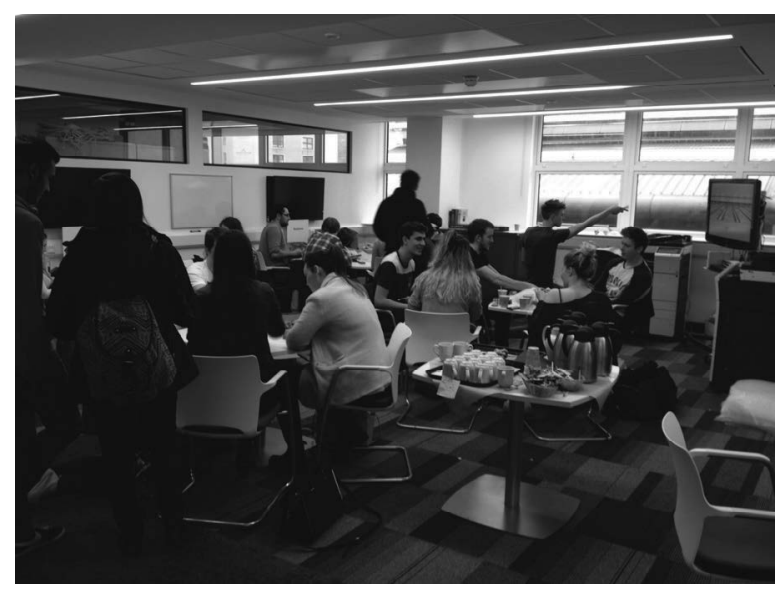

Figure 5. The final year de-stress day

\subsection{Rubik's cube championship}

Following on from the original Rubik's cube championship in 2012 (Cornock and Baxter, 2012) in which students from all year groups were invited to take part in the competition, the Maths Arcade 
ran another championship in March 2015. The move to the new location and the added incentive of inter-year rivalry saw the number of participants increase from four to twelve, which included teams from all year groups. Points were available for just taking part as well as extra points available for completing the cube within five minutes, two minutes and one minute. In addition to the students competing, the championship was also enjoyed by an audience of staff and students who didn't take part themselves. Feedback from the students included the following comments:

"It was really good to do something with the other year groups. I managed a personal best. More people showed up than the amount that attend arcade so there were lots of fresh faces." (Second year student)

"I watched it and it was a great atmosphere." (Final year student)

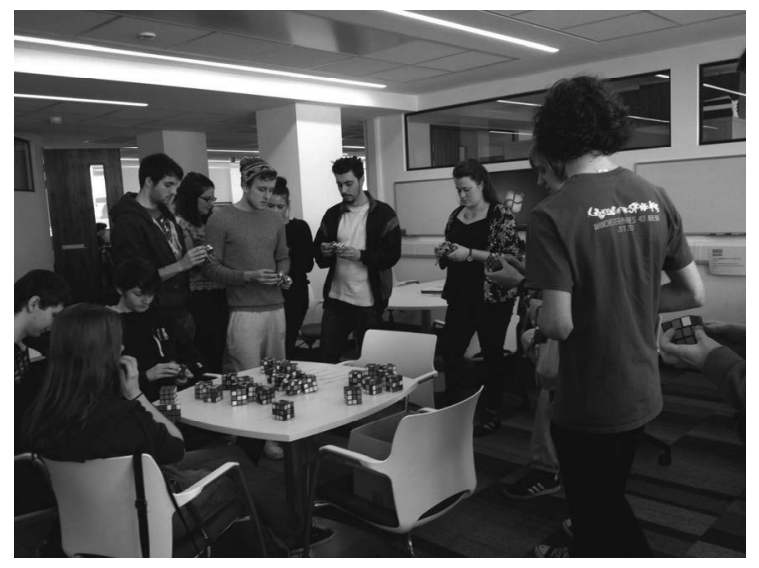

Figure 6. The Rubik's cube championship

\section{Further improvements}

The Maths Arcade at Sheffield Hallam University has become more successful since moving to the new space, but there are still further developments and improvements that can be made. Suggestions from students have included holding more specific events like the Rubik's cube championship for different games, having more tables in the area, holding more sessions and also longer sessions. There is a large demand for the Maths Arcade from students that aren't in the first year, especially since the move to the new space. The timetable for all students will be evaluated as the inter-year interaction should be encouraged further.

\section{References}

Bradshaw, N. (2011). The University of Greenwich Maths Arcade. MSOR Connections 11(3), 2629.

Bradshaw, N. and Rowlett, P. eds. (2012). Maths Arcade: stretching and supporting mathematical thinking. MSOR Network. Available via http://www.mathcentre.ac.uk/resources/uploaded/mathsarcade.pdf (last accessed 26 June 2015)

Cornock, C. and Baxter, E. (2012). Sheffield Hallam University 'Maths Arcade' - Feedback on a trial and plans to include in peer assisted learning. In: N.Bradshaw and P. Rowlett, eds. Maths Arcade: stretching and supporting mathematical thinking. MSOR Network. Available via http://www.mathcentre.ac.uk/resources/uploaded/mathsarcade.pdf (last accessed 26 June 2015) 
Waldock, J. (2010). Peer-Assisted Learning in Mathematics at SHU. In: M. Robinson, N. Challis and M. Thomlinson, eds., Maths at university: Reflections on experience, practice and provision. Birmingham, U.K.: More Maths Grads, pp. 85-88. Available via

http://aces.shu.ac.uk/support/staff/docs/MMG Case Studies Waldock PAL.pdf (last accessed 26 June 2015) 